Comment.- The persisting inward rotation of the eye appears to be due to stretching of the left external rectus muscle during the time that it was paralysed. And although the function appears to have fully recovered, the stretching has remained. In view of the surgical principle that paralysed muscles should be put at rest, it seems to me that the correct treatment in this case would have been to fix the eye with a suture in full outward rotation as soon as the paralysis was discovered. This would have prevented the stretching of the muscle. Unfortunately, I did not think of this until too late. But in any case, a fortnight after the accident was probably too long for any benefit to have resulted. The case, however, seems to point to the importance of early suture in a position of rest in cases of traumatic ocular paralysis.

\title{
A CASE OF BILATERAL BUPHTHALMIA WITH MULTIPLE CONGENITAL ABNORMALITIES IN ONE EYE
}

\author{
BY \\ G. G. PENMAN \\ LONDON
}

L. P., male, aged 6 years, attended at the Royal Westminster Ophthalmic Hospital on October 5, 1929. The parents said that for five years the child had had defective eyesight, and " would not look up."

Examination was extremely difficult on account of photophobia, but it was quite obvious that the condition was buphthalmia, in a very advanced state.

The child was admitted, and on October 9 was given a general anaesthetic and examined more thoroughly.

The right eye showed the ordinary features of an advanced case of buphthalmia; the cornea very large, steamy, and with many splits in Descemet's membrane, a very deep anterior chamber; fundus not visible. Tension, by Schiötz tonometer, $37 \mathrm{~mm}$. $\mathrm{Hg}$.

In the left eye, besides these features, there was almost complete aniridia, the rim of rudimentary iris showing as a dark brown border, except at about 11 o'clock, where there appeared to be a wider iris, from the anterior surface of which a strip of white anterior vascular sheath remnant, with some vessels on its surface, ran to the centre of the anterior surface of the lens. The edge of the lens presented below a double coloboma, the suspensory ligament being absent in that region. Tension was $30 \mathrm{~mm}$. $\mathrm{Hg}$. later.

The left eye was trephined the same day, and the right a week 


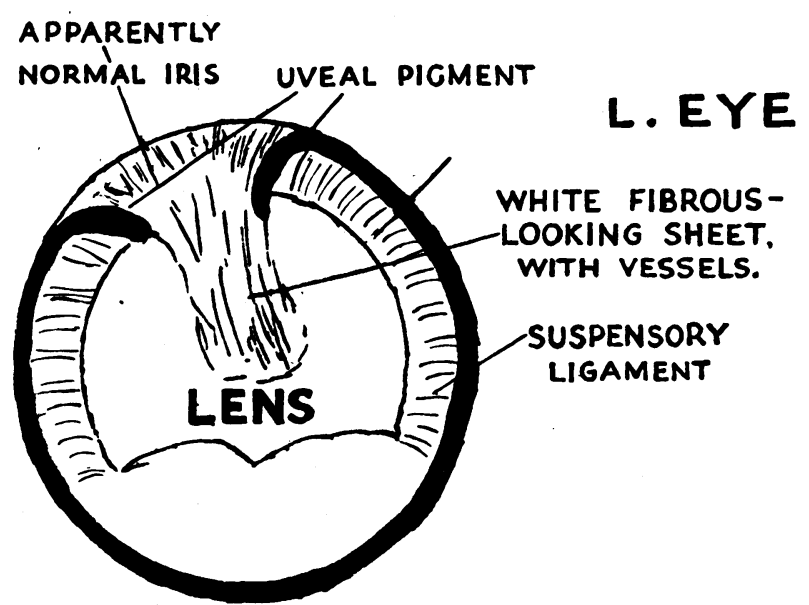

The tension after operation was much better in the right eye, varying from 15 to $23 \mathrm{~mm}$. $\mathrm{Hg}$. The left was not improved.

Seen in January, 1930, the child was still rather photophobic, but seemed to be using its eyes more, and was said by the parents to be seeing its food, toys, etc., quite well.

The case is interesting in view of the close connection of buphthalmia with congenital abnormalities; also the intense photophobia is not a usual symptom, but probably due to the excessive amount of light entering the left eye.

\section{ANNOTATIONS}

\section{Development of Ophthalmology in Europe}

Some interesting observations on this subject were made by Professor Fuchs in his dedicatory address at the opening of the Wilmer Ophthalmological Institute. Ophthalmology may justifiably be regarded as the senior speciality in medicine and surgery as it split away from its parent stem no less than three thousand four hundred years ago, in the time of dynastic Egypt. The use of copper sulphate in the treatment of what may truly be called Egyptian ophthalmia was well known in those days, when there were also a number of other specific cures for eye diseases, as described in the Papyrus Ebers. After the fall of the Roman Empire there was complete stagnation in ophthalmology which persisted until the middle ages when spectacles were invented, not by oculists but by physicists who based their work on Kepler's doctrines. Arabic oculists, though men of great fame in their time, did relatively nothing to advance matters, since they limited themselves to translating the books of ancient authors such as 